\title{
SINTESIS DAN ANALISIS HASIL UJI KARBON AKTIF BERBAHAN DASAR ORGANIK YANG BERBEDA-BEDA
}

\author{
Ainun Jariah $^{1}$, Hernawati ${ }^{1}$ \\ ${ }^{1}$ Jurusan Fisika UIN Alauddin Makassar \\ E-mail:ainunj26@mail.com
}

\begin{abstract}
Abstrak: Tujuan dari penelitian ini yaitu Untuk mengetahui perbandingan nilai kadar air dan nilai daya serap terhadap yodium dari bahan organic berbeda-beda, Untuk mengetahui bahan organik yang menghasilkan karbon aktif yang sesuai dengan SNI. Metode yang digunakan pada penelitian ini yaitu metode studi literatur menggunakan sepuluh jurnal yang berkaitan dengan penelitian sebagai sumber rujukan. Secara umum, penelitian dimulai dengan proses dehidrasi,kemudian proses karbonisasi dan diakhiri dengan proses aktivator. Dari hasil yang dipeoleh bahan organik yang paling baik untuk sintesis karbon aktif yang memenuhi SNI adalah ampas kopi dengan nilai kadar air sebesar 3,29\% dan daya serap terhadap yodium sebesar $750,24 \mathrm{mg} / \mathrm{g}$.
\end{abstract}

Kata Kunci : Bahan organik, Karbon aktif

\section{PENDAHULUAN}

\section{A. Latar Belakang}

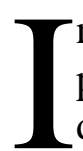

ndustri pembuatan karbon aktif di Indonesia telah mengalami kemajuan yang cukup pesat. Hal ini disebabkan oleh semakin meningkatnya permintaan pasar, baik di dalam negeri maupun untuk diekspor ke luar negeri. Peningkatan kebutuhan akan karbon aktif ini diakibatkan oleh semakin banyaknya aplikasi karbon aktif untuk industri dan berbagai peralatan bantu manusia. Karbon aktif dapat dipergunakan untuk berbagai industri, antara lain yaitu industri obat- obatan, makanan, minuman, pengolahan air (penjernihan air) dan lain-lain.

Untuk mengetahui bagaimana kualitas dari suatu bahan karbon aktif dilakukan pengujian yang hasilnya mengacu kepasa Standar Nasional Indonesia (SNI). Beberapa jenis pengujian fisis dari karbon aktif yaitu, pengujian nilai kadar air, kadar abu, kadar zat menguap, kadar karbon terikat, daya serap terhadap yodium, daya serap terhadap benzena.

Berdasarkan uraian diatas yang kemudian menjadi latar belakang dilaksanakannya studi literatur dengan membandingkan nilai pengujian fisis karbon aktif yang berasal dari bahan dasar organik.

\section{B. Rumusan Masalah}

Rumusan Masalah pada penelitian ini yaitu :

1. Berapa perbandingan nilai kadar air dan nilai daya serap terhadap yodium dari bahan organik? 
2. Bahan organik manakah yang menghasilkan karbon aktif yang sesuai dengan SNI?

\section{Tujuan Penelitian}

Tujuan dari penelitian ini yaitu :

1. Untuk mengetahui perbandingan nilai kadar air dan nilai daya serap terhadap yodium sesuai SNI.

2. Untuk mengetahui bahan organik yang menghasilkan karbon aktif yang sesuai dengan SNI.

\section{KAJIAN PUSTAKA}

\section{A. Integrasi Ayat}

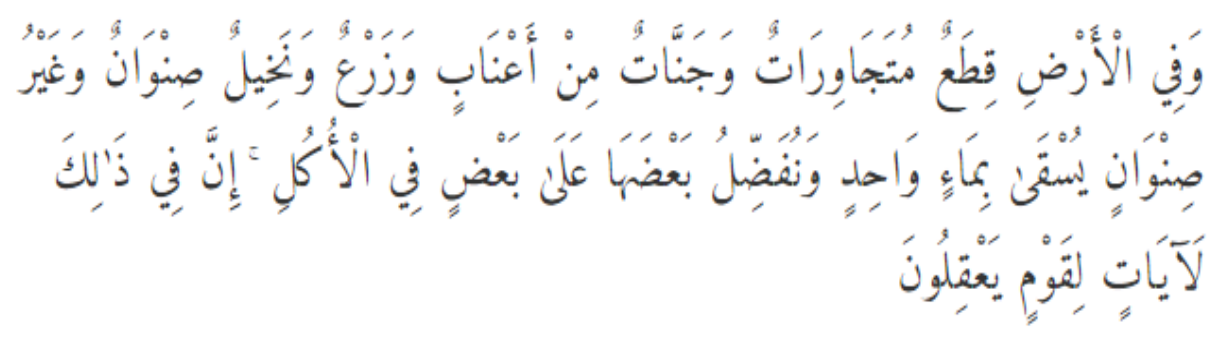

Terjemahnya :

"Dan di bumi ini terdapat bagian-bagian yang berdampingan, dan kebunkebun anggur, tanaman-tanaman dan pohon korma yang bercabang dan yang tidak bercabang, disirami dengan air yang sama. Kami melebihkan sebahagian tanamtanaman itu atas sebahagian yang lain tentang rasanya. Sesungguhnya pada yang demikian itu terdapat tanda-tanda (kebesaran Allah) bagi kaum yang berfikir" (Qs. Ar-Ra'd:4) (Departemen Agama RI, 2007).

Dalam tafsir al-Muntakhab, ayat ini sebagai pengisyaratan ilmu tentang tanah (geologi dan geofisika) dan ilmu lingkungan hidup (ekologi) serta pengaruhnya terhadap sifat tumbuh - tumbuhan. Secara ilmiah tanah persawahan terdiri atas butir butir mineral, air yang bersumber dari hujan, zat organik yang berasal dari limbah tumbuhan dan makhluk hidup. Lebih dari itu terdapat pula jutaan makhluk hidup yang tidak dapat dilihat mata telanjang. Memanfaatkan apa-apa yang telah Allah ciptakan merupakan salah satu sikap menghargai dan mensyukuri nikmat Allah. Benda-benda seperti limbah yang sering dianggap sesuatu yang tidak berguna sesungguhnya dapat dimanfaatkan jika mengetahui cara yang tepat dalam memanfaatkannya Sifat tanah yang bermacam-macam itu baik kimia, fisika maupun biologi menunjukkan kemahakuasaan Allah. Tanaman seperti kemiri diciptakan oleh Allah sungguh tidak siasia karena seluruh bagian tanaman ini dapat dimanfaatkan mulai dari buah, tempurung, daun. Namun masih banyak yang tidak menyadari akan kebesaran Allah terhadap ciptaan-Nya sehingga tempurung kemiri terkadang dianggap sebagai limbah dan tidak memiliki manfaat. Meskipun benda tersebut dianggap sebagai limbah yang tidak bermanfaat namun ketika diolah dengan cara yang benar maka benda limbah tersebut dapat menjadi bahan karbon aktif tempurung kemiri yang lebih ramah lingkungan. Hal tersebut dapat membuktikan bahwa sesungguhnya apa yang diciptakan oleh Allah swt. 
tidak ada yang sia-sia bagi orang-orang berakal. (Quraish Shihab, 2009).

\section{B. KarbonAktif}

Karbon aktif adalah suatu bahan yang berupa karbon amorf yang mempunyai luas permukaan yang sangat besar yaitu 300 sampai $2000 \mathrm{~m}^{2} / \mathrm{gr}$. Luas permukaan yang sangat besar ini disebabkan karena mempunyai struktur pori-pori. Pori-pori inilah yang menyebabkan karbon aktif mempunyai kemampuan untuk meyerap (Cheremisinoff,1993).

Karbon aktif adalah karbon yang diproses sedemikian rupa sehingga mempunyai daya adsorbsi yang tinggi. Karbon aktif berbentuk amorf. Karbon ini terdiri dari pelatpelat datar yang atom C-nya terikat secara kovalen dalam suatukisi heksagon. Pelatpelat ini bertumpuk satu sama lainnya membentuk kristal-kristal dengan sisa hidrokarbon yang tertinggal pada permukaan. Dengan menghilangkan hidrokarbonnya menyebabkan permukaan menjadi aktif._Struktur dasar karbon aktif adalah menyerupai struktur grafis murni.Kristal grafis terdiri dari lapisan-lapisan bidang heksagonal yang tersusun dari atom-atom karbon yang menyerupai cincin-cincin aromatis dalam senyawa organik. Bahan baku karbon aktif pada umumnya berasal dari senyawasenyawa organik seperti : tempurung kelapa, sekam padi, tongkol jagung, serbuk gergaji, dan lainlain.Selain itu juga karbon aktif berasal dari hewan, tumbuh-tumbuhan, limbah ataupun mineral yang mengandung karbon dapat dibuat menjadi arang aktif antara lain:tulang,kayu lunak, sekam, tongkol jagung, tempurung kelapa, sabut kelapa, ampas penggilingan tebu, ampas pembuatan kertas, serbuk gergaji, kayu keras dan batubara (Achmad, Z dan Kuntaarsa, A, 1994).

Adapun standar karbon aktif menurut SNI dapat dilihat pada Tabel berikut:

Tabel 1. Standar Karbon Aktif (SNI) 06-3730-1995

\begin{tabular}{lc}
\hline \multicolumn{1}{c}{ Jenis Persyaratan Parameter } & Parameter \\
\hline Kadar Air & Mak 15\% \\
\hline Kadar Abu & Mak 10\% \\
\hline Kadar Zat Menguap & Mak 25\% \\
\hline Kadar Karbon Terikat & Min 65\% \\
\hline Daya Serap Terhadap Yodium & Min 750 mg/g \\
\hline Daya Serap Terhadap Benzena & Min 25\% \\
\hline (R. Vinsiah,2015)
\end{tabular}

\section{Penggunaan Karbon Aktif}

Penggunaan karbon aktif dibagi atas 2 tipe yaitu:

1. Karbon aktif sebagai pemucat

Karbon aktif sebagai pemucat biasanya berbentuk powder yang sangat halus, diameter pori mencapai $1000 \mathrm{~A}^{\circ}$, digunakan dalam fase cair, berfungsi untuk memindahkan zat-zat pengganggu yang menyebabkan warna dan bau yang tidak diharapkan, membebaskan pelarut dari zat-zat pengganggu dan kegunaan lain yaitu pada industri kimia dan industri farmasi.Diperoleh dari serbuk-serbuk gergaji, ampas pembuatan kertas atau dari bahan baku yang mempunyai densitas kecil dan mempunyai struktur yang lemah. 
2. Karbon aktif sebagai penyerap uap

Biasanya berbentuk granular atau pellet yang sangat keras diameter pori berkisar antara 10-200 $\mathrm{A}^{\circ}$, tipe pori lebih halus, digunakan dalam fase gas, berfungsi untuk memperoleh kembali pelarut, katalis, pemisahan dan pemurnian gas. Diperoleh dari tempurung kelapa, tulang, batu bata atau bahan baku yang mempunyai bahan baku yang mempunyai struktur keras.Penggunaan karbon aktif dalam Industri pangan dan bukan pangan :

a. Penggunaan dalam Industri pangan:

1. Pemurnian minyak goring

2. Pemurnian gula

3.Penjernihan air

b. Penggunaan dalam industri bukan pangan:

1. Industri kimia dan farmasi

2. Katalis

Kapasitas serap arang aktif merupakan kemampuan arang aktif dalam menyerap substansi yang ada dalam lapisan kapasitas arang aktif. Semakin besar kapasitas serap arang aktif berarti arang aktif tersebut semakin baik digunakan sebagai adsorber (Sinaga,2003).

\section{Analisis Kadar Air}

Dalam penelitian Zulfadhli (2017) Karbon aktif ditimbang dan dimasukkan ke dalam cawan porselin, setelah itu dimasukkan ke dalam oven pada suhu $105^{\circ} \mathrm{C}$ selama 3 jam. Karbon aktif didinginkan dalam desikator dan ditimbang. Kadar air dapat dihitung dengan persamaan sebagai berikut:

Kadar air $=\frac{\mathrm{A}-\mathrm{B}}{\mathrm{A}} \times 100 \%$

\section{E. Uji Daya Serap terhadap Iodium}

Pengujian terhadap daya serap iodium dilakukan melalui tahapan sebagai berikut:

1) Karbon aktif ditimbang sebanyak 0,5 gram dan dicampurkan dengan $50 \mathrm{ml}$ larutan Iodium $0,1 \mathrm{~N}$, kemudian dikocok dengan alat pengocok selama 15 menit.

2) Setelah itu sampel disentrifuge sampai karbonnya turun.

3) Kemudian diambil $10 \mathrm{ml}$ larutan sampel dan dititrasi dengan larutan Natrium Tiosulfat $0,1 \mathrm{~N}$.

4) Jika warna kuning pada larutan mulai samar, ke dalam larutan tersebut ditambahkan larutan amilum 1\% sebagai indikator sehingga berwarna biru tua.

5) Larutan dititrasi kembali sampai warna biru tua berubah menjadi warna bening.

\section{F. Zat Aktivator}

Aktivator adalah zat atau senyawa kimia yang berfungsi sebagai reagen pengaktif dan zat ini akan mengaktifkan atom-atom karbon sehingga daya serapnya menjadi lebih baik. Zat aktivator bersifat mengikat air yang menyebabkan air yang terikat kuat pada pori-pori karbon yang tidak hilang pada saat karbonisasi menjadi lepas.Selanjutnya zat aktivator tersebut akan memasuki pori dan membuka permukaan arang yang tertutup. Dengan demikian pada saat dilakukan pemanasan, senyawa pengotor yang berada dalam pori menjadi lebih mudah terserap sehingga luas permukaan karbon aktif semakin besar danmeningkatkan daya serapnya .Menurut Kirk and Othmer (1978), 
bahan kimia yang dapat digunakan sebagai pengaktif diantaranya $\mathrm{CaCl} 2, \mathrm{Ca}(\mathrm{OH}) 2$, $\mathrm{NaCl}, \mathrm{MgCl} 2, \mathrm{HNO} 3, \mathrm{HCl}, \mathrm{Ca} 3(\mathrm{PO} 4) 2, \mathrm{H} 3 \mathrm{PO} 4, \mathrm{ZnCl} 2$, dan sebagainya. Semua bahan aktif ini umumnya bersifat sebagai pengikat air (Tri Kurni,dkk.2009).

\section{METODE EKSPERIMEN}

Metode yang digunakan dalam penelitian ini adalah metode study literatur dengan menggunakan beberapa referensi dari jurnal untuk mendapatkan hasil penelitian.adapun metode yang digunakan dalam penelitian jurnal yaitu sebgai berikut :

Secara umum proses Pembuatan Karbon Aktif ada 3 tahap yaitu:

\section{1) Proses Dehidrasi}

Adalah proses penghilangan air pada bahan baku. Bahan baku dipanaskan sampai temperatur $170^{\circ} \mathrm{C}$.

\section{2) Proses Karbonisasi}

Adalah proses pembakaran bahan baku dengan menggunakan udara terbatas dengan temperature udara antara $300^{\circ} \mathrm{C}$ sampai $900^{\circ} \mathrm{C}$ sesuai dengan kekerasan bahan baku yang digunakan. Proses ini menyebabkan terjadinya penguraian senyawa organik yang menyusun struktur bahan membentuk metanol, uap asam asetat, tar, dan hidrokarbon. Material padat yang tertinggal setelah proses karbonisasi adalah karbon dalam bentuk arang dengan permukaan spesifik yang sempit.

\section{3) Proses Aktivasi}

\section{a. Proses Aktivasi Fisika}

Pada proses aktifasi fisika, biasanya karbon dipanaskan didalam furnace pada temperatur $800-900^{\circ} \mathrm{C}$. Beberapa bahan baku lebih mudah untuk diaktifasi jika diklorinasi terlebih dahulu. Selanjutnya dikarbonisasi untuk menghilangkan hidrokarbon yang terklorinasi dan akhimya diaktifasi dengan uap.

\section{b. Proses Aktivasi Kimia}

Proses aktivasi kimia merujuk pada pelibatan bahan-bahan kimia atau reagen pengaktif. Kimia yang dapat digunakan sebagai pengaktif diantaranya $\mathrm{CaCl}_{2}, \mathrm{Ca}(\mathrm{OH})_{2}, \mathrm{NaCl}, \mathrm{MgCl}_{2}, \mathrm{HNO}_{3}, \mathrm{HCl}, \mathrm{Ca}_{3}(\mathrm{PO} 4) 2, \mathrm{H}_{3} \mathrm{PO}_{4}, \mathrm{ZnCl} 2$, dan sebagainya. Hessler (1951) dan Smith (1992) menyatakan bahwa unsur-unsur mineral activator masuk diantara plat heksagon dari kristalit dan memisahkan permukaan yang mula-mula tertutup. Dengan demikian, saat pemanasan dilakukan, senyawa kontaminan yang berada dalam pori menjadi lebih mudah terlepas. Hal ini menyebabkan luas permukaan yang aktif bertambah besar dan meningkatkan daya serap karbon aktif.

\section{HASIL DAN PEMBAHASAN}

\section{A. Hasil Pengamatan}

Berdasarkan studi literatur yang telah dikaji dari beberapa jurnal diperoleh data hasil pengujian karbon aktif seperti pada tabel berikut : 


\begin{tabular}{|c|c|c|c|c|c|}
\hline No & Nama peneliti & $\begin{array}{c}\text { Bahan } \\
\text { organik }\end{array}$ & $\begin{array}{c}\text { Jenis } \\
\text { Aktivator }\end{array}$ & $\begin{array}{l}\text { Kadar air } \\
(\%)\end{array}$ & $\begin{array}{c}\text { Daya Serap } \\
\text { Terhadap Yodium } \\
(\mathrm{mg} / \mathrm{g})\end{array}$ \\
\hline 1 & $\begin{array}{l}\text { Siti Jamilatun dan } \\
\text { Martomo (2014) }\end{array}$ & $\begin{array}{l}\text { Tempurung } \\
\text { kelapa }\end{array}$ & $\mathrm{Na}_{2} \mathrm{CO}_{3}$ & 1,61 & $159,72 \mathrm{mg} / \mathrm{g}$ \\
\hline 2 & 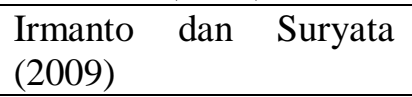 & Ampas kopi & $\mathrm{HNO}_{3}$ & 3,29 & $750,24 \mathrm{mg} / \mathrm{g}$ \\
\hline 3 & $\begin{array}{l}\text { Azhari, Fitri Kasih, } \\
\text { Arfenny Wisanti (2008) }\end{array}$ & $\begin{array}{l}\text { Tempurung } \\
\text { kemiri }\end{array}$ & $\mathrm{CaCl}_{2}$ & 2,48 & $175,5659 \mathrm{mg} / \mathrm{g}$ \\
\hline 4 & Siti Salamah (2008) & $\begin{array}{l}\text { Kulit buah } \\
\text { Mahoni }\end{array}$ & $\mathrm{KoH}$ & 13,31 & $384,38 \mathrm{mg} / \mathrm{g}$ \\
\hline 5 & $\begin{array}{l}\text { Muh. Zadhli dan Iriany } \\
(2017)\end{array}$ & Buah Karet & $\mathrm{H}_{3} \mathrm{PO}_{4}$ & 0,51 & \\
\hline 6 & $\begin{array}{l}\text { A.Fuandy Ramdja, } \\
\text { Mirah Halim, Jo Handi } \\
\text { (2008) }\end{array}$ & $\begin{array}{l}\text { Pelepah } \\
\text { kelapa }\end{array}$ & $\mathrm{Hcl}$ & 3,31 & $832,96 \mathrm{mg} / \mathrm{g}$ \\
\hline 7 & $\begin{array}{l}\text { Hafnidi Hasni Harahap, } \\
\text { Usman Malik, Rahmi } \\
\text { Dewi (2014) }\end{array}$ & Kelapa sawit & $\mathrm{H}_{2} \mathrm{O}$ & 4,5 & $353 \mathrm{mg} / \mathrm{g}$ \\
\hline 8 & $\begin{array}{l}\text { Beni Febriansyah, } \\
\text { Chairul,ST.,MT dan } \\
\text { Silvia Reni Yenti, M.Si }\end{array}$ & Kulit durian & $\mathrm{Fe}$ & 14,12 & $580,27 \mathrm{mg} / \mathrm{g}$ \\
\hline 9 & $\begin{array}{l}\text { Tri Kurni Dewi, Arif } \\
\text { Nurrahman, } \\
\text { pemana (2009) }\end{array}$ & $\begin{array}{l}\text { Kulit } \quad \text { ubi } \\
\text { kayu }\end{array}$ & $\mathrm{HCl}$ & 5,90 & $788 \mathrm{mg} / \mathrm{g}$ \\
\hline 10 & $\begin{array}{l}\text { Emmy Sahara, Ni } \\
\text { kadek, Ida Bagus Putra } \\
\text { Manuaba (2017) }\end{array}$ & Gumitir & $\mathrm{NaOH}$ & 1,25 & $199,97 \mathrm{mg} / \mathrm{g}$ \\
\hline
\end{tabular}

\section{B. Pembahasan}

Berdasarkan hasil pengamatan dengan metode studi literatur dari sepuluh jurnal,diperoleh tabel hasil pengamatan dimana nilai yang ditunjukkan untuk pengujian kadar air dan daya serap terhadap yodium telah memenuhi Standar Nasional Indonesia (SNI) dengan mengacu pada tabel II.1. Metode yang digunakan pada penelitian ini yaitu metode studi literatur menggunakan sepuluh jurnal yang berkaitan dengan penelitian sebagai sumber rujukan. Secara umum, penelitian dimulai dengan proses dehidrasi,kemudian proses karbonisasi dan diakhiri dengan proses activator

Dari hasil uji kualitas karbon aktif bahan organik yang menghasilkan karbon aktif yang paling mendekati SNI adalah hasil uji bahan organik ampas kopi yang menggunakan activator $\mathrm{HNO}_{3}$ dengan nilai kadar air 3,29\% dan daya serap terhadap yodium sebesar 750,24 mg/g. Hal ini disebabkan karena nilai kadar airnya lebih sedikit dan daya serap terhadap yodiumnya sesuai dengan nilai SNI. 


\section{PENUTUP}

\section{A. Kesimpulan}

Kesimpulan pada penelitian ini adalah :

1. Hasil uji nilai kadar air dan daya serap terhadap yodium dari bahan organik untuk sintesis karbon aktif telah memenuhi SNI dengan kadar air maks 15\% dan daya serap yodium min $750 \mathrm{mg} / \mathrm{g}$.

2. Bahan organik yang paling baik untuk sintesis karbon aktif yang memenuhi SNI adalah ampas kopi.

\section{B. Saran}

Saran pada percobaan ini yaitu sebaiknya menguji nilai kadar air,kadar abu, kadar zat menguap, kadar karbon terikat, daya serap terhadap yodium dan daya serap terhadap benzena agar sesuai dengan Standar Nasional Indonesia (SNI).

\section{DAFTAR PUSTAKA}

Achmad, Z dan Kuntaarsa, A. (1994). Pembuatan Arang Aktif dari Tempurung Kelapa. Jurusan Teknik Kimia, Fakultas Teknologi Industri,UPN'Veteran" Yogyakarta

Cheremisinoff, N. P. (1993). Carbon Adsorption of Pollutant Control. USA

Departemen Agama RI. (2007). Al-qur'an dan Terjemahan. Bandung: PT. Sygma Examedia Arkanleema.

DR. Abdullah bin Muhammad bin Abdurrahman bin Ishaq Al-Sheikh. (2004). Tafsir Ibnu Katsir Jilid 6. Bogor : Pustaka Imam asy-Syafi'i

H, Pohan. (1993). Prospek Penggunaan Karbon Aktif dalam Industri. Bogor : Warta IHP.

Muhammad Zulfadhli, Iriany. (2017). Pembuatan Karbon Aktif Dari Cangkang Buah Karet (Hevea brasilliensis) Dengan aktivator $\mathrm{H}_{3} \mathrm{PO}_{4}$ dan Aplikasinya Sebagai Penjerap Cr(VI). Jurnal Teknik Kimia USU, 6(1).

R. Vinsiah, Andi Suharman, Desi. (2015).Pembuatan Karbon Aktif dari Cangkang Kulit Buah Karet. Palembang. Universitas Sriwijaya.

Sembiring, Sinaga, (2003), Arang Aktif(Pengenalan dan Proses Pembuatannya). Jurusan Teknik Industri, Fakultas Teknik, Universitas Sumatera Utara.

Tri Kurnia Dewi, Arif Nurrahman, Edwin Permana. (2009). Pembuatan Karbon Aktif Dari Kuli Ubi Kayu (Mannihot esculenta)._Jurnal Teknik Kimia, 16(1). 